\title{
VISUAL FUNCTIONS IN APHAKIA AFTER SECONDARY INTRAOCULAR LENS IMPLANTATION
}

\author{
Hana Langrová, Dagmar Hejcmanová, Jaroslav Peregrin \\ Department of Ophtalmology, Charles University, Faculty of Medicine, Hradec Králové; \\ (Head: prof. MUDr. P. Rozsíval, CSc.)
}

\begin{abstract}
Summary: 21 aphakic eyes of 21 patients corrected by glasses (A-G) were examined 1 and 6 months before and after secondary intraocular lens implantation (SILI). Visual acuity (VA) was tested using Snellen chart and computerized method with Landolt rings (CL). Contrast sensitivity (CS) was measured using computerized Contrast sensitivity system 8010 in spatial frequencies from 0.74 to $29.55 \mathrm{c} / \mathrm{deg}$. Preoperative best corrected VA (BCVA) in A-G eyes was significantly lower in comparison with control group of the same age only using computerized method with Landolt rings. A reduction of BCVA by both methods at 1 month and its return to original values after 6 months were noted. Significantly lower values of CS were found in A-G patients before SILI compared to the control group of the same median age in spatial frequencies from 3.69 to $29.55 \mathrm{c} / \mathrm{deg}$. After 1 and 6 months the values stayed on the preoperative level, except the frequency 29.55 $\mathrm{c} / \mathrm{deg}$, which increased significantly $(\mathrm{p}<0.01) 6$ months after SILI.
\end{abstract}

Key words: Aphakia; Secondary intraocular lens implantation; Contrast sensitivity; Visual acuity; Landolt rings

\section{Introduction}

Traditional aphakic spectacle correction is generally not acceptable because of induced anisometropia as great as $25 \%$ - $35 \%$ (7). Contact lens correction is satisfactory for many patients, but for those who cannot manipulate a contact lens because of tremor or arthritis, those whom inconvenience and the expense of multiple lens replacements become a burden, or those who are unable to tolerate a contact lens for other reasons, the aphakic eye is functionaly blind (2). For these patients and for those who require improved uncorrected vision and stereopsis for occupational or psychological reasons, the remaining treatment option is secondary intraocular lens implantation.

In our clinic SILI is made both in aphakic eyes after intracapsular or extracapsular cataract extraction in the past and in aphakic eyes after injury if there were no contraindications like chronic uveitis or disorganized anterior chamber. The patients before SILI were given complete ophthamologic examination including slit lamp, ophthalmoscopy, tonometry and biometry. Uncorrected VA (UNVA) and BCVA were tested using common Snellen chart. Postoperative examinations were on 1. day then on 1 . week and 1. month by ambulant ophthalmologist.

It is questionable to which extent it is possible the VA tested by means of Snellen chart or on Landolt rings (1) hold for a sufficiently sensitive sign of potential discrete vi- sual changes that we expected in A-G after SILI. For such a study the examination of CS is more suitable because it offers information on the resolving power of the eye at submaximal contrasts of the environment and on a larger area of the retina which is after Arden (1) more important.

We decided to complete the evaluation of the results of SILI in A-G eyes using computerized method with Landolt rings (9) and computerized method for CS.

\section{Materials and method}

1. 21 aphakic eyes of 21 patients corrected by glasses were examined before and 1 month after SILI, 18 eyes also after 6 months. Median age of the 10 women and 11 men was 70 years (range $50-83$ ). BCVA before SILI was $6 / 12$ and better using Snellen chart, only in one case was BCVA 6/15. In 18 cases were the eyes aphakic after intracapsular cataract extraction (ICE), in 3 cases after extracapsular cataract extraction (ECE), so in 18 cases were implanted lens into anterior chamber, in 3 cases posterior chamber lenses. In no eye clinically signigficant macular pathology was seen.

As a control group were examined 20 eyes of 20 people with normal intraocular findings with no clinically significant macular pathology and BCVA $6 / 9$ or better using Snellen chart. There were 10 women and 10 men with median age of 70 years (range 54 - 81 years). 
2. UCVA and BCVA using Snellen chart and computerized method with Landolt rings were tested. CS was tested using computerized Contrast sensitivity 8010 system (Neuroscientific corp., Farmingdale, USA) in spatial frequencies from 0.74 to $29.55 \mathrm{c} / \mathrm{deg}$.

The distance for examination of VA using computerized method was 4 meters. The patient determined the position of the gap in Landolt rings that could be in one of four basic directions. After two right answers followed Landolt ring of a half size (means about three lines smaller). This preparatory phase continued till the subject did a mistake. Then a measuring phase started in which after two right determinations followed Landolt ring smaller by one line, after one wrong answer was Landolt ring about one line greater generated. In the end of the programm threshold VA was determined (9).

The distance for examination of CS was 2.2 meters so that the range of spatial frequencies from 0.74 to 29.55 c/deg was achieved when the size of monitor was $5 \times 3.5$ angular degrees. An adjustement method with ascendent and descendent approach of the threshold contrast determination was used (8).

\section{Results}

\section{Visual acuity}

- BCVA using Snellen chart in the control group was 6/9 and better, in A-G patients $6 / 12$ and better, in one case $6 / 15$.

- BCVA in A-G eyes was significantly lower compared to the control group of the same median age only using computerized method with Landolt rings ( $p<0.05$ ).

- 1 month after SILI BCVA decreased by both methods, significantly only using computerized method ( $p<0.05$ ).

- after 6 months BCVA returned to its preoperative level using both methods (Tab.1, Tab.2, Fig.1).

In both terms after SILI no significant differences in VA between patients with anterior and posterior chamber lenses were detected.

Tab. 1: The number of eyes with BCVA $6 / 6,6 / 9,6 / 12$, $6 / 15,6 / 18$ and 6/24 using Snellen chart in A-G eyes before SILI and 1 and 6 months after SILI.

\begin{tabular}{|c|c|c|c|c|c|c|}
\hline \multicolumn{1}{|c|}{ Group } & $6 / 6$ & $6 / 9$ & $6 / 12$ & $6 / 15$ & $6 / 18$ & $6 / 24$ \\
\hline $\begin{array}{c}\text { A-G before } \\
\text { SILI (n = 21) }\end{array}$ & 1 & 10 & 9 & 1 & - & - \\
\hline $\begin{array}{c}\text { A-G 1 month } \\
\text { after SILI (n = 21) }\end{array}$ & 1 & 10 & 6 & 2 & 1 & 1 \\
\hline $\begin{array}{c}\text { A-G 6 months } \\
\text { after SILI (n=18) }\end{array}$ & 1 & 11 & 4 & 1 & - & 1 \\
\hline
\end{tabular}

Tab. 2: Comparison of VA of control group and A-G patients before and 1 and 6 months after SILI using Snellen chart (Sn) and computerized method with Landolt rings (CL).

\begin{tabular}{|c|c|c|}
\hline $\begin{array}{c}\text { Group } \\
\text { Control group } \\
(\mathrm{n}=20)\end{array}$ & $\begin{array}{c}\log \text { MAR }(\mathrm{Sn}) \\
0,18 \pm 0,13\end{array}$ & $\begin{array}{c}\log \text { MAR }(\mathrm{Cl}) \\
0,03 \pm 0,13\end{array}$ \\
\hline $\begin{array}{c}\text { A-G before } \\
\text { SILI }(\mathrm{n}=21) \\
\text { stat. significance }\end{array}$ & $\begin{array}{c}0,26 \pm 0,11 \\
\text { n.s. }\end{array}$ & $\begin{array}{c}0,14 \pm 0,18 \\
(\mathrm{p}=0,021)\end{array}$ \\
\hline $\begin{array}{c}\text { A-G before } \\
\text { SILI (n = 21) }\end{array}$ & $0,26 \pm 0,11$ & $0,14 \pm 0,18$ \\
\hline $\begin{array}{c}\text { A-G 1 month } \\
\text { after SILI ( }=21) \\
\text { stat. significance }\end{array}$ & $\begin{array}{c}0,29 \pm 0,20 \\
\text { n.s. }\end{array}$ & $\begin{array}{c}0,26 \pm 0,17 \\
(\mathrm{p}=0,021)\end{array}$ \\
\hline $\begin{array}{c}\text { A-G 6 month } \\
\text { after SILI ( }=18) \\
\text { stat. significance }\end{array}$ & $\begin{array}{c}0,21 \pm 0,09 \\
\text { n.s. }\end{array}$ & $\begin{array}{c}0,16 \pm 0,16 \\
\text { n.s. }\end{array}$ \\
\hline
\end{tabular}

(n. s. ... nonsignificant differences)

Fig. 1: Visual acuity values (in $\log$ MAR units) using Snellen charts $(\mathrm{Sn})$ and computerized method with Landolt rings (CL). The control group consisted of 20 persons, A-G group of 21 persons. ( * ... p $<0.05$ )

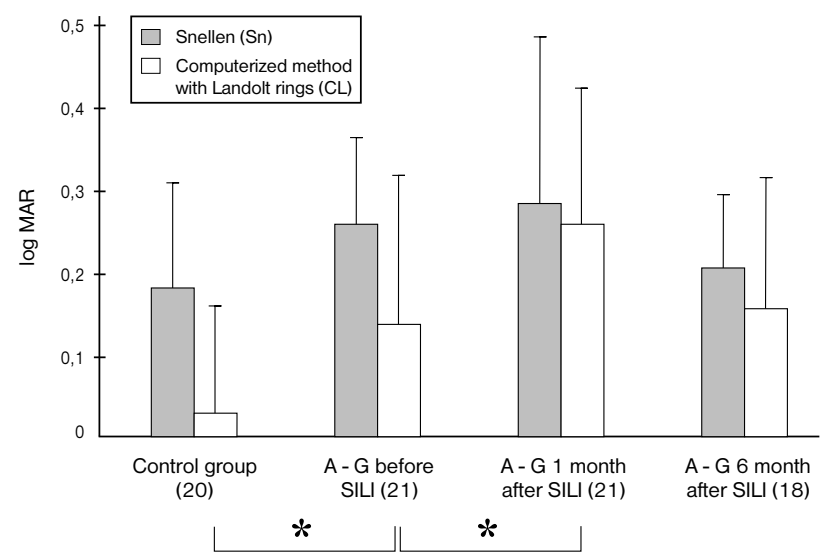

\section{Contrast sensitivity}

- CS in aphakic eyes was significantly lower compared to the control group, especially in moderate and higher spatial frequencies (Fig.2).

- Nonsignificant changes of CS in both terms after SILI were noted except of the value in frequency $29.55 \mathrm{c} / \mathrm{deg}$ which increased significantly 6 months after SILI (Fig.3).

There were no significant differences in CS between patients with anterior and posterior lenses detected. 
Fig. 2: Contrast sensitivity (CS) values in decibels (dB) for spatial frequencies of $0.74,1.97,3.69,7.39,14.77$ and $29.55 \mathrm{c} / \mathrm{deg}$. The differences in CS between the control group (black diamond) and A-G patients (white rectangle) before SILI are statisticaly significant at spatial frequencies from 3.69 to $29.55 \mathrm{c} / \mathrm{deg}$. (* ... p < 0.05 , ** ... p $<0.01$, $* * * \ldots \mathrm{p}<0.001)$

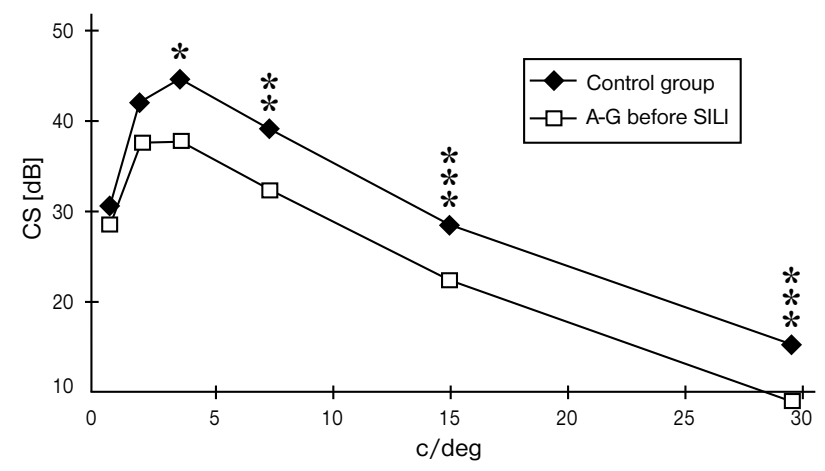

Fig. 3: The changes of CS in decibels (dB) after SILI were nonsignificant except of significant increase of the CS in frequency $29.55 \mathrm{c} / \mathrm{deg}$ after 6 months. $(* * \ldots \mathrm{p}<0.01)$

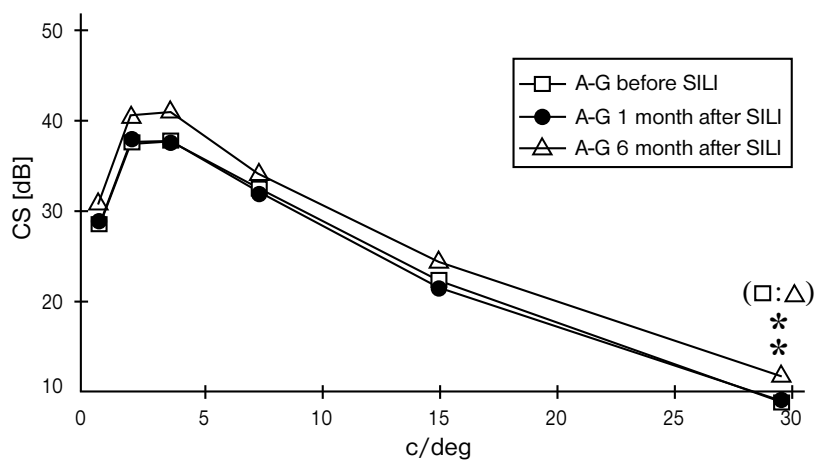

\section{Discussion}

We noted significantly lower values of VA in A-G eyes compared to the control group of the same median age using computerized method with Landolt rings, significant reduction of BCVA 1 month after SILI only using computerized method and the return of BCVA 6 months after SILI to original values by both methods used. BCVA 20/40 and better have $80.9 \%$ of patients 1 month after SILI and $88.8 \%$ of patients after 6 months.

Our results are comparable to those of Durrie et al.(2) who described that $73 \%$ of the patients receiving intraocular lenses had postoperative BCVA equal to or better than their preoperative BCVA and $70 \%$ of the patients had VA $20 / 40$ or better.

In this study statistically lower values of CS from 3.69 to $29.55 \mathrm{c} / \mathrm{deg}$ in A-G eyes compared to the control group of the same median age and no statistically significant changes of CS except of the frequency $29.55 \mathrm{c} / \mathrm{deg}$ after SILI are demonstrated.
Contrary to us Hejcmanová et al.(4) found nearly identical values in CS curve when comparing CS in A-G eyes with phakic eyes of the same median age using Vistech charts in spatial frequencies from 1.19 to $27.25 \mathrm{c} / \mathrm{deg}$. Only in frequency $7.97 \mathrm{c} / \mathrm{deg}$ the aphakic group has a statistically lower CS $(p<0.05)$. The artephakic patients with a retropupillary lens have, when compared with a control group have lowered CS approximately by one third. Also Hess et al. (5) registered a reduction of CS in patients after ECE with anterior chamber lens and Howe et al. (6) saw reduction of CS after ECE with posterior chamber lens.

Identically with us Owsley et al. (9) found normal values of CS not only on ECE with retropupillary lens but also after ICE with anterior chamber lens. Also Furuskog and Nilsson (3) did not find even after repeated control examinations of the patients after ECE with retropupillary lens statistically significant differences compared to the control group of the same median age.

\section{Conclusion}

Our resuts indicate that SILI both with anterior chamber lens and posterior chamber lens is a very effective method for the treatment of aphakia from the functional point of view.

\section{Acknowledgement}

This work was supported by the Grant of Charles University (Grant No 59/97).

\section{References}

1. Arden GB. The importance of measuring contrast sensitivity in cases of visual disturbance. $\mathrm{Br} \mathrm{J}$ Ophthalmol 1970;82:198-209.

2. Durrie DS, Habrich DL, Dietze TR. Secondary lens implantation vs. epikeratophakia for the treatment of aphakia. Am J Ophthalmol 1987;103:284-391.

3. Furuskog P, Nilsson BY. Contrast sensitivity in patients with posterior chamber intraocular lens implant. Acta Ophthalmol 1988;66:438-444.

4. Hejcmanová D, Peregrin J, Svěrák J, Hartmann M. Contrast sensitivity in aphakias and artephakias (in Czech). Cesk Ophthalmol 1991;47:138-143.

5. Hess RF, Woo GC, White PD. Contrast attenuation characteristics of iris clipped intraocular lens implants in situ. Br J Ophthalmol 1985;69:129-135.

6. Howe JW, Mitchell KW, Mahabaleswara M, AbdelKhalek MN. Visual evoked potential latency and contrast sensitivity in patients with posterior chamber intraocular lens implants. Br J Ophthalmol 1986;70:890-4.

7. Kaufman HE. The correction of aphakia. Am J Ophthalmol 1980;89:1.

8. Langrová H, Hejcmanová D, Peregrin J. Reproducibility of contrast sensitivity testing (in Czech). Cesk Ophthalmol 1996;3:152-7. 
9. Owsley C, Gardner T, Sekuler R, Lieberman H. Role of the crystalline lens in the spatial vision loss of the elderly. Invest Ophthalmol Vis Sci 1985;26:1165-70.

10. Peregrin $\mathrm{J}$ et al. Contrast sensitivity of dialysed patients (in Czech). Cesk Ophthalmol 1989;45:412-5.

11. Peregrin J et al. Determination of the visual acuity using computer (in Czech). Cesk Ophthalmol 1991;47:13-20.

Submitted August 1997.

Accepted September 1997.

MUDr. Hana Langrová,

Department of Ophthalmology,

Charles University, Faculty of Medicine, 50005 Hradec Králové, Czech Republic. 